Trong khi đó, ít phổ biến hơn, đầu in kép có thể đùn hai hay nhiêu loại filaments riêng biệt, luân phiên hoặc đồng thời trong quá trình in (hình 2B). Nhờ vậy, có thể tách biệt mực in có chứa các nguyên liệu tương ky hoặc cho phép in vật thể có nhiều phần mà mỗi phần được tạo thành từ các nguyên liệu khác nhau.

*Hoàn thiên sản phẩm: Trong một số trường hợp, vật thể in có hình dạng phức tạp hoăcc diên tích bề mặt in nhỏ khiến cho in lớp đâu tiên khó khăn hoặc vật thể in không định hình vững chắc trên bàn in. Trong trường hợp này, có thể tạo các khung đõ định hình cấu trúc của vật hoặc hỗ trợ các lớp đầu liên kết với bề mặt bàn in. Những vật liệu định hình này sẽ được loại bỏ sau khi quá trình in kết thúc. Tùy thuộc vào nguyên liệu cấu thành, vật liệu trung gian có thể bị loại bỏ bằng cách bẻ gãy hoặc hòa tan trong nước ấm [8]. Bên cạnh vệ sinh loại bỏ các vật liệu trung gian, giai đoạn hoàn thiện có thể gồm công đoạn thêm những đặc tính mới cho sản phẩm, như đánh bóng, bao film, bao màu...

\section{KẾT LUÂ̂N}

Cơ chế hoạt động của kỹ thuật in 3D FDM tương đối đơn giản, dễ điều khiển và có thể kiểm soát hoàn toàn bằng phần mềm. Kỹ thuật này cho phép tạo ra các vật thể có cấu trúc phức tạp với độ chính xác cao từ các mô hình 3 chiều. Đặc tính của vật in có thể được điều chỉnh linh hoạt thông qua điều chỉnh thiết kế của vật in cũng như thay đổi các thông số điều khiển quá trình in. Việc hiểu rõ nguyên lý cấu tao, quy trình hoạt động là rất cần thiết trong việc làm chủ công nghệ và kiểm soát quá trình hoạt động nhằm đảm bảo chất lượng sản phẩm tốt và độ lặp lại cao. Công nghệ này mở ra hướng hiện đại hóa ngành công nghiệp sản xuất thuốc theo hướng tạo ra các dạng thuốc có cấu trúc phức tạp và cá nhân hóa điều trị trong chăm sóc y tế.

TÀI LIỆU THAM KHẢO

1. Katstra, W., Palazzolo, R., Rowe, $C_{\text {., }}$ Giritlioglu, B., Teung, P., and Cima, M. (2000). Oral dosage forms fabricated by Three Dimensional Printing ${ }^{\mathrm{TM}}$. Journal of controlled release $66,1-9$.

2. Gaisford, A.W.B.a.S. (2018). 3D printing of pharmaceuticals.

3. Goyanes, A., Buanz, A.B., Hatton, G.B., Gaisford, S., and Basit, A.W. (2015). 3D printing of modified-release aminosalicylate (4-ASA and 5-ASA) tablets. European Journal of Pharmaceutics and Biopharmaceutics 89, 157-162.

4. Goyanes, A., Buanz, A.B., Basit, A.W., and Gaisford, S. (2014). Fused-filament 3D printing (3DP) for fabrication of tablets. International journal of pharmaceutics 476, 88-92.

5. Gioumouxouzis, C.I., et al. (2018). "A 3D printed bilayer oral solid dosage form combining metformin for prolonged and glimepiride for immediate drug delivery.". European Journal of Pharmaceutical Sciences, 120, 40-52.

6. Aho, J., et al. (2019). "Roadmap to 3D-printed oral pharmaceutical dosage forms: feedstock filament properties and characterization for fused deposition modeling." Journal of pharmaceutical sciences, 108, 26-35.

7. Xu, P., et al. (2020). "Development of a quantitative method to evaluate the printability of filaments for fused deposition modeling 3D printing.". International journal of pharmaceutics, $588,119760$.

8. Gebhardt, A., and Jan-Steffen Hötter. (2016). Characteristics of the Additive Manufacturing Process, Additive Manufacturing D, 3, 21-91.

\title{
HIỆU QUẢ CHE TUỶ TRỰC TIẾP BẰNG VÂTT LIỆU CALCIUM SILICATE (BIODENTINETM) TRÊN RẲNG VĨNH VIỄN CÓ VIÊM TUỶ KHÔNG HỒI PHỤC
}

\section{TÓM TĂT}

Mục tiêu: Đánh giá hiệu quả che tuỷ trực tiếp bằng vật liệu calcium silicate (Biodentine ${ }^{T M}$ ) trển răng người trưởng thành có viêm tuỷ không hôi phục. Đối tượng và phương pháp nghiên cứu: Bênh nhân nữ 24 tuổi có cơn đau tự phát, kéo dài, xuất hiện

*Đai Hoc Y Dước Tp.Hồ Chí Minh

Chịu trách nhiệm chính: Trần Xuân Vĩnh

Email: vinhdentist@yahoo.com

Ngày nhận bài: 13.4.2021

Ngày phản biên khoa hoc: 27.5 .2021

Ngày duyệt bài: 14.6.2021

\section{Trần Xuân Vĩnh*}

nhiều lần cách đây 2 tuần. Dựa trên khám lâm sàng và hình ảnh $X$ quang, răng được chẩn đoán viêm tuỷ không hồi phục. Sau khi gây tê và đặt đê cao su, phân ngà sâu và mô tuỷ viêm được loại bỏ bằng mũi khoan vố trùng và tay khoan cao tốc dưới nguồn nước. Cầm máu trong vòng 2 phút bằng gòn thấm $\mathrm{NaOCl} 2,5 \%$. Tuỷ lộ được che bằng vật liệu Biodentine ${ }^{T M}$. Sau 1 tháng, răng được trám kểt thúc với resin composite. Kết quả: Ngày đâuu tiên sau can thiêp, bênh nhân chỉ đau nhẹ. Theo dõi sau 1 tháng, 6 tháng và 24 tháng, răng không có triệu chứng bất thường, đáp ứng với thử nhiệt hoặc điện. Hình ảnh trên phim $X$ quang vùng quanh chóp bình thường. Kêt luận: Che tuỷ trực tiếp với vật liệu Biodentine ${ }^{T M}$ trên răng trưởng 
thành được chẩn đoán viêm tuỷ không hồ phục có thế là một giải pháp lựa chọn thay thế cho điều trị nội nha.

Tư khoá: Biodentine ${ }^{\mathrm{TM}}$, che tuỷ trực tiếp, viêm tuỷ không hồi phụ, điều trị bảo tổn tuỷ sống

\section{SUMMARY \\ EFFECT OF DIRECT PULP CAPPING USING CALCIUM SILICATE BASED MATERIAL (BIODENTINETM) IN MATURE PERMANENT TOOTH WITH IRREVERSIBLE PULPITIS \\ Objectives: Evaluation of effect of direct pulp capping using calcium silicate based material (Biodentine $^{\mathrm{TM}}$ ) in mature permanent tooth with irreversible pulpitis. Methods: A 24-year-old female patient presented with a main complaint of severe spontaneous and lingering pain in tooth number 46, occurring several times over the previous two weeks. Based on the clinical and radiographic examinations, tooth was diagnosed with irreversible pulpitis. The tooth was anaesthetized before placement rubber dam for isolation. Decayed tissues were removed using a sterilized high-speed round bur under water coolant. The bleeding was arrested after about two minutes by gently pressing a sterile cotton pellet soaked in $2,5 \%$ sodium hypochlorite. The exposed pulp was capped with Biodentine ${ }^{\mathrm{TM}}$. The tooth was finally restored with resin composite after one month. Results: The patient reported the mild pain occurred for the first post treatment day, but pain was soon alleviated. Clinical and radiographic evaluation was completed at 6 months and 2 year postoperatively. The patient had no complaint about the tooth, positive responses to cold and electric pulp tests, and periapical radiographs showed no periapical lesion after one year. Conclusion: The direct pulp capping using Biodentine $^{T M}$ in mature permanent tooth with irreversible pulpipis can be an alternative option to root canal therapy.}

Tư khoá: Biodentine ${ }^{\mathrm{TM}}$, direct pulp capping, irreversible pulpitism, vital pulp therapy

\section{I. ĐẶT VẤN ĐỀ}

Điều trị tuỷ răng sống bao gồm che tuỷ gián tiếp, che tuỷ trực tiếp, lấy tuỷ buồng bán phần hoặc toàn bộ. Điều trị tủy răng sống được thực hiện nhằm bảo tồn và duy trì sự sống của mô tủy bị tổn thương do sâu răng, chấn thương hay do thủ thuật điều trị. Điều này từng được khuyến cáo ở trẻ em có chóp răng chưa phát triển đầy đủ và răng được chẩn đoán viêm tuỷ có hồi phục. Trường hợp răng được chẩn đoán viêm tuỷ không hồi phục, chỉ định thường là lấy tuỷ toàn bộ (điều trị nội nha). Tuy nhiên, răng sau khi điều trị nội nha mất mô nhiêu, yếu và dể gãy hơn so với rắng còn tuỷ sống. Nhiêuu nghiên cứu đã chứng minh tỉ lệ thất bại của điều trị nôi nha đối với bác sĩ tổng quát cao hơn so với bác sĩ chuyên về nội nha $[1,2]$. Hơn nữa, điều trị nội nha mất nhiều thời gian, chi phí nhiêu. Gần đây với sự phát triển của vật liệu hoạt tính sinh học calcium silicate và sự hiểu biết về tế bào gốc răng. Nhiều nghiên cứu lâm sàng và sinh học đã chứng minh tuỷ của răng trưởng thành bị lộ do sâu răng có thể lành thương và tái tạo, và phương pháp điều trị bảo tồn tuỷ răng sống không chỉ áp dụng trên răng chưa đóng chóp viêm tuỷ có hồi phục mà có thể thực hiện thành công trên răng đã đóng chóp viêm tuỷ không hồi phục $[3,4]$.

Mineral trioxide aggregate (MTA) có thành phần chính calcium silicate, là lựa chọn tối ưu như một vật liệu che tuỷ trực tiếp, được xem là "chuẩn vàng". MTA có khả năng kích thích tạo ngà sửa chữa giúp bảo về mô tuỷ còn sống bển dưới [5]. Tuy nhiên, MTA có nhiêu nhược điểm như: thời gian đông cứng lâu, khó thao tác, làm đổi màu răng. Môt phiên bản mới của vật liệu calcium silicate - Biodentine ${ }^{\mathrm{TM}}$ (Septodont, SaintMaur-des-Fosses, France) ra đời nhằm khắc phục các nhược điểm của MTA. Biodentine ${ }^{T M}$ có đặc tính sinh học giống với MTA nhưng dễ thao tác, thời gian đông nhanh, không gây đổi màu răng và đăc tính cơ học được cải thiện [6].

Phương pháp che tuỷ trực tiếp với vật liệu calcium silicate để bảo tồn tuỷ răng sống trong trường hợp răng viêm tuỷ không hồi phục vẫn chưa được áp dụng rộng rãi trong thực hành nha khoa. ở Việt nam, vấn đề này chưa được quan tâm và ứng dung trong điều tri. Ca lâm sàng trong báo cáo này sẽ trình bày hiệu quả của che tuỷ trực tiếp bằng Biodentine ${ }^{T M}$ trên răng viêm tuỷ không hồi phục và qui trình thực hiện lâm sàng.

\section{II. ĐỐI TƯỢNG VÀ PHƯƠNG PHÁP NGHIÊN CỨU}

Bệnh nhân nữ 24 tuổi, có cơn đau tự phát xuất hiện nhiều lần trong vòng 2 tuần. Khám lâm sàng răng 46 có sang thương sâu răng lớn. Hình ảnh $X$ quang quanh chóp cho thấy sang thương sâu ngà sâu, gần sát tuỳ, vùng quanh chóp bình thương (Hình 1). Răng có đáp ứng với thử tuỷ. Dựa trên khám lâm sàng và hình ảnh $X$ quang, răng được chẩn đoán là viêm tuỷ không hồi phục. Bệnh nhân được giải thích và đồng ý với phương pháp điều trị che tuỷ trực tiếp với Biodentine $^{T M}$ để bảo tuỷ răng sống thay vì điều trị nội nha

Răng được gây tê với Lidocaine Hydrochloride $2 \%$ và Epinephrine 1:100,000 (Septodont, SaintMaur-des-Fosses Cedex, France), sau đó cô lập bằng cách đặt đê. Mô ngà sâu được loai bỏ bằng tay khoan cao tốc với mũi khoan tròn vô trùng. Phần tuỷ lộ và xoang được rửa sach với $\mathrm{NaOCl}$ 2,5\%. Máu chảy do tuỷ lộ được kiểm soát trong vòng 2 phút với gòn vô trùng thấm $\mathrm{NaOCl} 2,5 \%$. 
Phần tuỷ lộ được che với Biodentine ${ }^{T M}$ (Septodont, Saint-Maur-des-Fosses Cedex, France). Biodentin ${ }^{T M}$ cũng được dùng như vật liệu trám tạm lấp đầy xoang trám. Sau 1 tháng, phần Biodentine ${ }^{T M}$ bề mặt được lấy bớt, để lại lớp bên dưới dày khoảng $3 \mathrm{~mm}$ và trám kết thúc với resin composite (3M ESPE, St Paul, MN, USA) (Hình 2). Bênh nhân được theo dõi và tái khám sau 6 tháng và 2 năm.

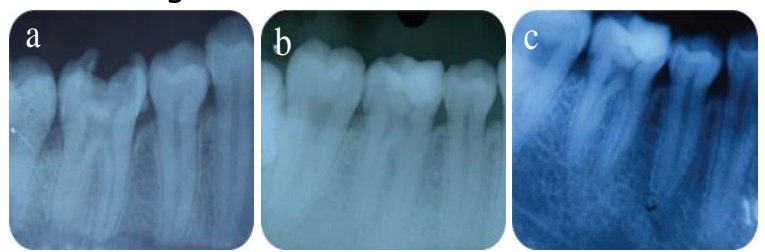

Hình 1 : X quang răng 46 a. trước điều trị, $\boldsymbol{b}$. sau 6 tháng; c. sau 2 năm

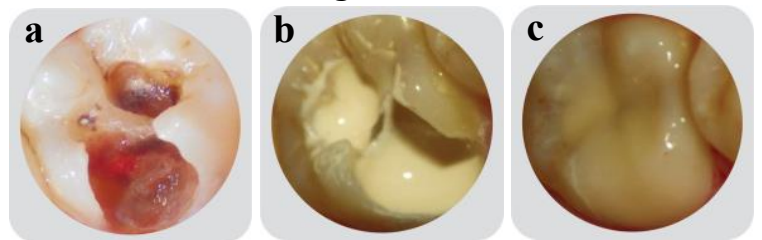

Hình 2: Hình trong miệng răng 46. a. trước điều tri; b.trám Biodentine ${ }^{T M}$; c. trám resin composite

\section{KẾT QUẢ NGHIÊN CứU}

Ngày đầu tiên sau khi trám, bệnh có đau nhẹ, sau đó ăn nhai binh thường. Sau 2 năm, bệnh nhân không có triệu chứng gì bất thương, ăn nhai bình thương. Hinh ảnh $X$ quang mô quanh chóp bình thường.

\section{BÀN LUÂ̂N}

Thành công của trường hợp lâm sàng này cung cấp thêm chứng cứ khoa học quan trong về tính hiệu quả của che tuỷ trực tiểp trên răng viêm tuỷ không hồi phục, đã được báo cáo bởi nhiều tác giả trước đây [3]. Trong trường hợp lâm sàng của chúng tôi, bệnh nhân than phiền có cơn đau tự phát và kéo dài, đau khi ăn nhai. Hình ảnh phim $X$ quang cho thấy sâu ngà sâu sát tuỷ, mô quanh chóp bình thường. Với triệu chứng lâm sàng và kết quả hình ảnh $X$ quang, răng được chẩn đoán là viêm tuỷ không hồi phục và trường hợp này hiện nay ở Viêt nam và cả trên thế giới thường được chỉ định điều trị nội nha. Kết quả của một nghiên cứu tổng quan của Aguilar và CS. (2011) về điều trị bảo tồn tuỷ răng sống trên người trưởng thành có viêm tuỷ không hồi phục cho thấy tỉ lệ thành công đạt $72,8 \%-99,4 \%$, trong đó che tuỷ trực tiếp có tỉ lệ thành công sau 1- 2 năm là $95,4 \%$ và sau $2-3$ năm là $87,3 \%$.

Một trong những nguyên nhân thất bại của điêu trị bảo tồn tuỷ là sự tạo vi kẽ giữa giao diện răng và phục hồi. Biodentine ${ }^{\mathrm{TM}}$ là vật liệu có khả năng bám dính cao, đề kháng với tạo vi kẽ. So với MTA, Biodentine ${ }^{\mathrm{TM}}$ có các đặc tính cơ lý đã được cải thiện như: dễ thao tác, độ cứng cao, thời gian đông cứng nhanh, không gây đổi màu răng [6]. Biodentine ${ }^{\mathrm{TM}}$ có thể sử dụng như vật liệu trám trong vòng 6 tháng, được xem là vật liệu "thay thế ngà răng". Trong nghiên cứu của chúng tôi, Biodentine ${ }^{T M}$ được sử dụng đồng thời như vật liệu che tuỷ và vật liệu trám tạm. Bênh nhân được hẹn trở lại sau 1 tháng, là thời gian đủ để đánh giá sự lành thương ban đầu và đáp ứng của mô tuỷ trước khi trám kết thúc với resin composite. Nhiều nghiên cứu trước đây đã chứng minh Biodentin ${ }^{\mathrm{TM}}$ tao ra môi trường lành thương tốt, kích thích tao ngà sửa chữa khi sử dụng che tuỷ lộ được tao ra trên răng chuột. Cấu trúc ngà sửa chữa liên tục với ngà nguyên phát giúp bảo về mô tuỷ lành bên dưới $[3,7]$.

Nghiên cứu mô học chứng mình rằng mô tuỷ cách vùng tuỷ viêm vài milimet vẫn lành mạnh không có vi khuẩn. Nếu mô tuỷ viêm được loại bỏ, che với vật liệu thích hợp thì phần tuỳ lành mạnh còn lại bên dưới có thể bảo tồn [8]. Trong nghiên cứu của chúng tôi, phần tuỳ viêm đã được loại bỏ, và tuỷ lộ được che với vật liệu calcium silicate hoat tính sinh học, được bít kín đề kháng với sự tao vi kẽ. Bên cạnh tính bám dính cao vào mố răng, Biodentine ${ }^{\mathrm{TM}}$ có khả năng kháng viêm, kiểm soát sự tiết các yếu tố viêm và sự huy tụ các tế bào viềm, giúp tao môi trường lành thương mô tuỷ tốt.

Sự thành công của che tuỷ trục tiếp được đánh giá bằng triệu chứng lâm sàng và $X$ quang. Răng đáp ứng với thử tuỷ lạnh hoặc điện, răng không có triệu chứng và hình ảnh $X$ quang bình thường, không có sang thương quanh chóp. Sự kiểm soát chảy máu sau khi loại bỏ phần tuỳ viêm cũng là yếu tố quan trọng để đánh giá mức độ viêm và tiên lượng sự lành thương. Nếu cầm máu không thành công sau 10 phút thì sẽ không chỉ định che tuỷ trực tiếp mà phải thực hiện thủ thuật điều trị khác như lây tuỷ buồng hoắc nội nha thông thường.

\section{KẾT LUẬN}

Với sự phát triển của vật liệu hoat tính sinh học calcium silicate và sinh học mô tuỷ, che tuỷ trực tiếp bằng Biodentine ${ }^{T M}$ trên răng được chẩn đoán viêm tuỷ không hồi phục là một tiếp cận mới thay thế cho điêu trị nội nha. Các nghiển cứu lâm sàng với số lượng ca lớn và theo dỗi lâu dài là cần thiết. 
TÀI LIÊU THAM KHẢO

1. Al-Omiri, M.K.; Mahmoud, A.A.; Rayyan, M.R.; Abu-Hammad, $O$. Fracture resistance of teeth restored with post-retained restorations: an overview. Journal of endodontics 2010, 36, 1439-1449.

2. Bjørndal, L.; Reit, C. Endodontic malpractice claims in Denmark 1995-2004. International endodontic journal 2008, 41, 1059-1065.

3. Aguilar, P.; Linsuwanont, P. Vital pulp therapy in vital permanent teeth with cariously exposed pulp: a systematic review. Journal of endodontics 2011, 37, 581-587.

4. Matsuo T, Nakanishi T, Shimizu H, Ebisu S. A clinical study of direct pulp capping applied to carious-exposed pulps. J Endod 1996;22:551-6.

5. Tran, X.V.; Gorin, C.; Willig, C.; Baroukh, B.; Pellat, B.; Decup, F.; Opsahl Vital, S.; Chaussain, C.; Boukpessi, T. Effect of a calcium- silicate-based restorative cement on pulp repair. Journal of dental research 2012,91, 1166-1171.

6. Pradelle-Plasse, N.; Tran, X.V.; Colon, P.; Laurent, P.; Aubut, V.; About, I.; Goldberg, M. Emerging trends in (bio) material research. Biocompatibility or Cytotoxic Effects of Dental Composites, 1st ed. Oxford, UK: Coxmoor Publishing Company 2009, 181-203.

7. Tran, X.V.; Salehi, H.; Truong, M.T.; Sandra, M.; Sadoine, J.; Jacquot, B.; Cuisinier, F.; Chaussain, C.; Boukpessi, T. Reparative mineralized tissue characterization after direct pulp capping with calcium-silicate-based cements. Materials 2019, 12, 2102.

8. Ricucci, D.; Loghin, S.; Siqueira Jr, J.F. Correlation between clinical and histologic pulp diagnoses. Journal of endodontics 2014, 40, 1932-1939.

\section{KẾT QUẢ HÓA TRỊ BỔ TRỢ TRƯớC PHÁC ĐỒ 4AC-4T Ở BỆNH NHÂN UNG THƯ VÚ GIAI ĐOẠN TIẾN TRIỂN TẠI CHỖ}

\section{TÓM TẮT}

Mục tiêu: Mô tả một số đặc điểm lâm sàng, cận lâm sàng của bênh nhân ung thư vú (UTV) giai đoạn tiến triển tại chỗ và đánh giá kết quả hoá trị bổ trợ trước phác đồ $4 A C-4 T$ và tác dụng không mong muốn ở nhóm bệnh nhân $(B N)$ trên. Đối tượng và phương pháp nghiên cứu: Nghiên cứu mô tả cắt ngang hồi cứu trên 52 BN UTV giai đợn tiến triển tại chỗ được hóa tri bổ trơ trước phấu thuât phác đồ $4 A C-4 T$ (Docetacel) tại bệnh viện K3. Kết quả: Đặc điểm nhóm nghiên cứu: Tuổi trung bình BN: 49,6 tuổi, phần lớn BN ở giai đoạn III $(96,1 \%)$ trong khi 3,9\% BN ở giai đoan IIB, 96,2\% BN có thể mô bênh học là ung thư biểu mô xâm nhập típ NST, đa sổ BN có độ mô học II $(73,1 \%)$. Đáp ứng: Sau điêu trị hóa chất, tî lệ người bệnh đáp ứng hoàn toàn (ĐƯHT) trên lâm sàng tăng từ $5,8 \%$ sau 4 đợt hóa trị lên $26,9 \%$ sau 8 đợt hóa trị. Có 1 BN tiến triển lâm sàng sau điêuu trị 8 chu kỳ hóa chất. Cả 52 BN đều được phẫu thuật sau hóa trị. ĐƯ'HT trên mô bệnh học đạt 28,8\%. Độc tính: BN trong nghiên cứu dung nạp khá tốt với phác đồ hóa chất. Tî lệ hạ bạch câu và hạ bạch câu đa nhân trung tính thường gặp độ 1,2. Tỉ lệ hạ bạch câu độ 3,4 trên tổng số chu kỳ hóa chất là $6,7 \%$ và $1,2 \%$. Nôn, chán ăn là những tác dụng không mong muốn thường gặp khi điều trị, tuy nhiên chỉ ở độ 1 và độ 2 . Rụng tóc gặp ở tất cả các $B N$, phân lớn là rụng gân hết hoặc

\section{${ }^{1}$ Trường Đại học Y Hà Nội \\ ${ }^{2}$ Bệnh viện $K$ \\ ${ }^{3}$ Bềnh viền Bach Mai}

Chịu trách nhiệm chính: Nguyễn Thị Phương Thảo

Email: thaophuong2705@gmail.com

Ngày nhận bài: 15.4.2021

Ngày phản biên khoa học: 28.5.2021

Ngày duyệt bài: 15.6.2021 toàn bộ. Kết luận: Phác đồ 4AC-4Docetacel được chứng minh có hiệu quả, độc tính của phác đồ chẩp nhận được, do vậy có thể áp dụng trong điều trị bổ trợ trước phẫu thuật UTV giai đoạn tiến triển tại chỗ trong điều kiện hiện nay ở nước ta.

Tư khóa: Ung thư vú giai đoạn tiến triển tại chỗ, điều trị bổ trợ trước, phác đồ 4AC-4Docetacel.

\section{SUMMARY \\ EFFICACY OF NEOADJUVANT 4AC-4T REGIMENT IN LOCALLY ADVANCED BREAST CANCER}

Objectives: Our study aims to describe the clinical and paraclinical characteristics of locally advanced breast cancer patients and evaluate the treatment outcomes and toxicity of neoadjuvant 4AC4T regiments in this group. Patients and Methods: Retrospective, descriptive study on 52 patients with locally advancer breast cancer, were treated with neoadjuvant 4AC-4T regiment at National Cancer Hospital. Results: The mean age was 49,6 . The majority of them were in stage III $(96,1 \%)$ while $3,9 \%$ patients were in stage IIB. $96,2 \%$ patients's histology were invasive carcinoma of no special type (NST) and $73,1 \%$ was in grade II. After treatment, the complete clinical response rised from 5,8\% (after 4 cycles of AC) to $26,9 \%$ (after 8 cycles of $4 A C$ 4Docetacel). There was 1 patients progressed during 4 docetacel cycles. All of our patients were moved to modified radical mastectomy after neoadjuvant chemotherapy. The pathological complete response (pCR) rate was $28,8 \%$. Most adverse events were manageable and tolerable. The most common toxicity was neutropenia with grade 1,2 . Non hematological toxicities such as vomiting, fatigue and alopecia were also common and all of them were mild and moderate. Conclusion: In locally advanced breast 